\title{
The MRCPsych Examination: Time for Change?
}

The College recently appointed a Working Party under the chairmanship of Professor Robert Cawley to review the MRCPsych Examination. We have invited four College members to contribute their views on this most important subject. We would welcome further views and invite readers to participate in the debate through our correspondence columns.

\section{Mark Aveline, Consultant Psychotherapist, St Ann's Hospital, Nottingham}

Examinations loom large in the minds of trainees. Rightly, trainees see passing the MRCPsych as official confirmation that they have successfully concluded their period of general professional training and may now advance to higher training and, almost inevitably, to Consultant status. They may assume, and in this the College does nothing to dissuade them, that they have been tested in the skills needed to practise psychiatry. Enumeration of such facts as are to be enumerated and the observation of external behaviour stand high in the lexicon of success. Listening and understanding, tolerance and compassion are also-runs. The examination does not merely reflect the form of the training but dictates the order of priorities. What the exam values, the trainee values. What the exam ignores, the trainee, unless strongly motivated, will be tempted to ignore.

The proper scope of psychiatry resists definition. Within the specialty, enthusiasts have, at times, over-extended the boundaries to encompass the genesis of civilization and the politics of society. Others have taken a narrower perspective, focusing on psychosis, organic and functional, phenomena which fit easily into the cognitive set acquired in medical training. Outside psychiatry, society encourages us to grapple with social ills and with those who disrupt the webb and waft of communal life. Psychologists would confine us to the so-called 'medical conditions' and social workers warn us of the dangers of becoming agents of the State.

What cannot be denied is the simple reality of psychiatry as demonstrated by our patients. Neurosis and personality disorder outnumber psychosis tenfold. For every patient treated by psychiatrists, ten more suffer their ills in the community. Demographic changes and temporal vulnerability increase the proportion of organic states in the young and the old. The spectrum in psychiatry ranges from the organic with genetic, structural and biochemical causation through the functional to the majority grouping of what is best described as 'problems in living'. However, with each state, the patient is a person first and foremost. Furthermore, his or her personality, expectations and environment will be crucial determinants in what happens when help is sought. The variety of individual problems demands a similar variety of intervention, carefully chosen to meet the biological, social and personal aspects of the case.

As a psychotherapist, I have a particular interest in the nature of the individual, what interactions have shaped him, what problems he faces, who shares his life and how he experiences his life. My focus is on inner experience and what a person is doing and could be doing with his life. I do not expect everyone else to share equally my fascination or to devote his professional life to this type of work. What I do want is that the psychiatrist in training recognizes, in a way that the MRCPsych does not currently encourage, the importance of subjective experience, the value of a helpful relationship, and the ease with which conflicts and prejudices in the doctor lead to a breakdown in communication.

Young psychiatrists generally have an interest in people and not just in disease processes. They begin to explore their patient's situation. However, all too often, they get out of their depth and panic. Through youth, they may face a situation beyond their experience, or, more fundamentally, outside their own culture. Personal maturation includes acceptance and integration of all aspects of one's self. At all stages in life, it is difficult to listen to another when his conflict coincides with one's own. The tendency is to disengage abruptly or to become over-involved and then disengage. Either way the patient is not well served. Supervision by someone interested in these aspects of interaction helps the trainee through the crisis and averts a damaging disengagement. Going further, a therapeutic relationship lays the foundation for personal change and a more fruitful life.

As the exam stands, it is possible to pass after only two years' experience in psychiatry. Typically the trainee will gain experience in acute, medium and long-stay psychiatry and psychogeriatrics, all predominantly in the atypical setting of a mental hospital. With luck the trainee will work in child and adolescent psychiatry, mental handicap, addiction, and rarely, but with good fortune, psychotherapy! Attachment follows attachment at six-month intervals; a 'hit and run'-'I'm only here for a few months'-style of practice is thereby encouraged, a style which ill-prepares the trainee for the long-term responsibilities of the consultant. The invaluable and relevant opportunity of regularly seeing patients of all kinds, the chronically depressed and psychotic as well as patients in psychotherapy, over two to three years is lost. In 1971, the Psychotherapy Section of the College recommended that trainees undertake under expert supervision the treatment of at least two individual cases and a psychotherapy group, and become familiar with other forms of psychotherapy. How- 
ever, in the absence of any institutional requirement in the exam for psychotherapy, the trainee may well not have this crucial experience.

Is the position any better when the exam is reached? Both Preliminary Test and Membership Examination rely heavily on multiple choice questions. I doubt that this form of question is appropriate in psychiatry. I suspect that the relevance of a question is in inverse proportion to its factual precision. Also, the format implies a false degree of certitude in a subject which, in practice, depends upon fine choice, the weighing up of factors and alternatives. Fortunately this aspect, together with the fundamental ability to communicate clearly and show critical judgement is preserved in the essay questions. The Clinical Examination could provide an opportunity to evaluate the interactive skills of the trainee. In practice, categorical diagnosis takes pride of place and phenomenology is taken to mean only external behaviour and not also inner experience as Jaspers originally described. How well the trainee related with the patient is not a formal objective. The relative importance given to that interaction may be judged by the fact that only two of the 87 College examiners are psychotherapists-one a psychoanalyst, the other primarily a behaviourist. In theory, my criticism could be partly met by a more vigorous use of the two sponsorship statements that accompany the trainees' application to sit the Membership Examination. Sadly trainees continue to pass who are distinctly lacking in the very ordinary qualities of interest in others, optimism, tolerance and compassion.

Other countries have developed novel solutions which we would do well to consider. The Australian and New Zealand College of Psychiatrists has for several years required the trainee to submit a casebook of cases personally treated by the candidate. The case histories must be of a satisfactory standard before the candidate can attempt the written examination. Ten case histories are required, each being between two and eight thousand words in length. They cover the diagnosis, investigation and treatment of a range of cases. Specifically, they must include one patient with an acute psychiatric disorder admitted for the first time to an inpatient psychiatric unit, one on a long-stay ward, one aged less than 14 years, one with organic CNS disease related to his psychiatric illness and one treated by psychotherapy for a minimum of approximately 50 sessions.

If, as I would like to see, this practice was adopted here, two advantages would follow. Clinical skills would be given greater emphasis and, certainly in the psychotherapy case, trainees would have to sit down and talk with their patients over an extended period of time. Lest this be seen as opening the door to esoteric abstraction, the Australian assessor, John Ellard (1979), has stated his objectives simply: 'Psychiatrists have to give some thought to how people feel and in particular how they feel themselves... One of the central skills in psychiatry is the ability to be aware of such things, to understand them, and to be comfortable with them.' Ellard wants to see at least a glimmer of the candidate's humanity. He marks down candidates who cannot clearly state the principles that they are using in the therapy, who pathologically adhere to dogma and who, in that process, abandon commonsense.

My second innovation comes from Canada. There, the candidate has to interview a patient in front of two examiners. The two examiners can either be present in the room or observe behind a one-way screen, as the candidate chooses. The examiners make independent assessments against which the examinee has the right of appeal. The assessments rate the quality of the relationship established between doctor and patient, taking into account the patient's attitude. In our present system, such an examination would be testing in every sense for the candidate, but with practice what was unusual would become familiar. In addition, what was undervalued would take its proper, prime place.

I do not view examinations as ends in themselves. Rather I see them appropriately confirming a seal of approval on what has gone before in the period of training. Supervised work with our patients is the great educator. I would add the caveat that this work should be undertaken with a degree of healthy scepticism and critical appraisal. The role of exams is to codify what is to be learnt and to lend weight to the various objectives. It follows that the shape of the education is of greater importance than the fact of the exam. What further refinements might be introduced into the training?

To begin with, we should encourage those doctors who would be best suited to the practice of psychiatry to enter the specialty. I suggest that these would be mature individuals with a good experience of life, divergent thinkers who are able to tolerate ambiguity and confusion and who favour nurturance over examination. Women may do better with these criteria than men.

If we wish to redress the inbalance in training towards psychotic states, the first year should be spent in out-patient and community based work. Only later would come in patient and long-stay work.

In 1911, Adolf Meyer was appointed to the Chair of Psychiatry at Johns Hopkins. His teaching stressed the psychobiological understanding of the individual and the ways used by him to maintain homeostasis during the events of a life-time. In an exemplary fashion he began with the patient's own exposition of his problems, evaluated his assets as well as his liabilities and instructed his trainees to study equally normal and abnormal behaviour. That emphasis on normality in its myriad forms is lacking in our present system. His most radical innovation was to make the study of personality central. Trainees not only made personality studies of three of their peers but began the process of understanding and integration with an autobiographical essay. What our predecessor did so well, we can now emulate.

Refrerence
EuARe, J. (1979) Writing up a peychoherapy case. A ustralla and New Zealand Journal
of Psychiain, i3, IS-19. 


\section{Frank Margison, Chatrman, Collegiate Trainees Committee*}

APIT was originally set up in response to strong feelings among trainee psychiatrists that the MRCPsych was a bad and unnecessary examination. A decade later APIT is in abeyance at a time when the College has set up a working party to review the structure of the examination. Within the College, the Trainces Committee (CTC) has played an active part in pushing for this review and has contributed ideas about changing the format of the exam. However, one of the problems facing the CTC is adequate representation of the range of trainees' views. Many trainees are conservatives, particularly those trainees who have not taken the exam; they say 'Better the Devil you know.' On the opposite wing are the radicals who declare that the exam should be scrapped and replaced by some form of continuous assessment. A group of elitists say that we should copy the Civil Service and have a system whereby 'high flyers' are selected and groomed for high office by allowing them to take the exam early. The 'hard liners', rare among trainces, say that the exam should be stifiened up into a harsher initiation rite, like the MRCP.

With this diversity of opinion all I can do is to make explicit some of the priorities for the CTC and make some general points about the nature of the exam. The CTC is concerned to change the exam in three main ways:

(i) to make the exam clearly based on clinical skills,

(ii) to review critically the purpose of the exam, and

(iii) to assess the exam as though it were a scientific instrument by questioning its validity and reliability.

(i) To make the exam more clinically relevant we have supported the idea of assessing basic practical skills such as interviewing and formulation possibly with the aid of standardized clinical material on videotape. MCQs are a relatively easy way of obtaining high reliability, but we have severely questioned the evidence that they are valid discriminators in the assessment of clinical expertise. This is difficult to know because the MCQ tends to be used as the criterion against which other parts of the exam are judged!

Although the views here are based on discussions with the CTC they are primarily those of the author. (ii) The above points need to be seen in the context of the purpose of the MRCPsych. The ostensible function is to provide a 'gate' through which pass candidates fitted for Higher Psychiatric Training and implicitly for eventual consultant posts. The less clearly stated functions are at least as important. The nature and content of the exam set a model into which many trainees fit themselves. The present model they see is of a fact-oriented scientific discipline with only peripheral attention paid to clinical ability. Examining boards elsewhere have tackled this difficult problem by developing exams which emphasize clinical ability as much as factual knowledge; they have asked semistructured questions about clinical problems, direct assessment of clinical skills, and videotaped 'short cases.'

(iii) It is also important that the exam is respected. In general the exam successfully picks out the very good and the very bad (although anecdotal evidence puts this in doubt at times). The exam must in addition be shown to be discriminating in the 'middle range' of candidates. Many trainees feel that the present exam is a lottery, unfortunately for high stakes. It would be difficult for the College to show that this were not so as the validity of the exam is assessed only by its internal consistency and not by any external criterion of clinical ability. In addition, for reasons of expense, the examiners are not adequately calibrated against each other. The most glaring example of this is the insistence of examiners that 'the method of formulation' is used when they are unable to agree among themselves what this means. The CTC is strongly against the concept of "high flyers' being institutionalized in the exam.

We are against 'tinkering' with the exam but feel that the College is taking a major, constructive step in reviewing the whole structure of the exam. The opportunity should also be taken to question its underlying purpose and function. It is important that trainees should use this opportunity to push the exam into a form which refiects the nature of psychiatry as a clinical discipline, in a reliable and consistent way. Trainees should feel free to lobby their representatives locally and nationally so that their views can be considered within the College.

\section{Chris Thompson, Honorary Senior Registrar, Bethlem and Maudsley Hospitals}

The most radical suggestion that one can make about the MRCPsych examination is that it should be abolished. In the early days of the College it was APIT's view that there was no need for an examination, and that the exercise constituted a monumental piece of ladder retraction by those who were already in consultant posts. Taking over from the old DPM, and to some extent the old MPhil examinations, the MRCPsych, with the backing of the College, has however prospered and is now the foremost postgraduate clinical examination in psychiatry.

Apart from elevating the standing of the profession by supplying its practitioners with impressive pieces of paper to 
hang on their walls, has this change raised the standard of the profession? One might argue that it has not, and that the examination has in fact retarded the development of psychiatric training. The argument would have it that trainees spend too much time nowadays 'swotting up' on virtually irrelevant so-called facts at the expense of developing an effective clinical style. Once they have these pseudofacts at their finger tips they consider themselves trained. Professionalism, on the other hand, is concerned with the gradual development, through practice and experience as well as through reading and research, of clinical competence, self-criticism and an eagerness to discover more about one's subject. The desire of some members and inceptors of the College to develop a syllabus for the MRCPsych might be held to demonstrate the distance by which our current position differs from that of a profession.

Let me say that I put the abolition of the MRCPsych forward as a radical possibility and not one to which I personally subscribe, although I do not believe that its effects on standards are entirely beneficial. How might one therefore change the examination to make it a better representation of clinical and academic competence without doing away with it altogether? Clearly the way to do this is to have a tighter assessment of what goes on in the real clinical situation. The clinical part of the examination at the moment represents nothing so much as a game. Candidates who treat it as a test of their abilities as psychiatrists often start by asking open questions as taught in the best centres. These candidates usually fail. Those who treat it as a game and go for direct questions with high information content such as 'have the doctors told you your diagnosis?' are more likely to pass-is this fair? In one way it is fair because the latter are obviously better prepared, but it shows that this part of the exam is not a good test of real clinical ability. The examination itself is modelled on the MRCP. Would not the MRCGP exam be a better model? General practitioners have to keep a $\log$ book of 50 cases which must be submitted prior to the examination. Likewise, psychiatric nurses have to do a case study. Why shouldn't candidates for the MRCPsych be expected to write, say, a 1,500-word case report or a series of perhaps five consecutive admissions to either hospital or out-patients? In addition it might be made compulsory before entry to the examination to have satisfied a College-appointed assessor at the place of work that one is clinically competent. Most training hospitals already have regular assessments which could be modified to provide this information. These two changes together might provide a fairer assessment of the candidate's clinical skill than the unrepresentable procedure we currently endure.

Is it not strange that psychiatrists who, more than any other branch of the profession, should be aware of the unreliability of interviews as examination techniques, persist with this bizarre, persecutory ritual of the viva voce? If one abolishes the clinical examination, the case reports which might replace it could be discussed in a modified viva which would then become a joint viva/clinical exam, on the principle that the two combined might do less harm than when administered separately.

I dealt with the orals first because they are the least satisfactory part of the examination. Next comes the MCQ. What a ludicrous way to test psychiatric knowledge. Even in general medicine where, let's face it, the facts are a little more secure, there are difficulties with ambiguity and inaccuracy in multiple choice questions. How can this be prevented in psychiatry without resorting to such silly games as matching theories with the names of their originators? At least essays test the candidate's ability to string words together, and also probably do test a limited number of subjects in greater depth. Perhaps, however, four subjects per candidate is rather a narrow range! Why not resolve this by having a short answer paper which would seem ideally suited to psychiatric material, combining a range of topics with the opportunities for free expression.

Let me make two more suggestions. Examiners need training to examine fairly. Many need to learn how to encourage the candidate who is in difficulty rather than to persecute him. The aim is to find out what a candidate knows, not how far to the right his Yerkes-Dobson curve is shifted. It might even be an idea to have trainees present in the clinical viva as umpires to make sure that play is fair. These trainees would obviously have to have passed the MRCPsych. If examiners are fair at the present, I fail to see what opposition there could be to this suggestion.

Certainly one widespread malpractice could be prevented in this way, that of asking the candidate at which hospital he works. It is often the case that candidates from large training hospitals go to one or two nearby examination centres. In some of these centres all their candidates are from top quality teaching centres. The examiners here generally operate at a much higher standard than those who are seeing a more representative mixture of candidates. Nobody likes to be seen as uncritical so most examiners will aim for the magic 50 per cent pass rate, either lowering or raising their standard accordingly. This failure to mix candidates penalizes the better centres and fails to put pressure on poorer centres to improve their training. I suggest that the allocation of candidates to centres within each Division is randomized in order to avoid these problems. I have not mentioned the research option which is quite rightly to be scrapped and therefore is beyond criticism.

The opinions expressed above are not necessarily my own nor those of trainees in general. I put them forward solely for the sake of the debate, which, if it is to be useful, must take into account all the possibilities-even the most unpalatable. There is a chance now to change the examination; let us hope it is a change for the better! 


\section{Sir William Trethowan, Professor of Psychiatry, University of Birmingham}

One of the College's more far-sighted moves in respect of its examination for Membership was to make provision for an on-going statistical analysis of the results, so that each fresh exam could be compared with its predecessors and any emerging trends observed. This analysis has from the start been in the hands of Dr Christine Hassall, Senior Research Fellow in the Department of Psychiatry at Birmingham University, who has already published much of the data gleaned from the first nine Preliminary Tests and Membership Examinations. However, as 20 such Tests and Examinations have now been completed such conclusions in this paper as are derived from the on-going statistical analysis are based largely on Exam numbers 10 to 20 .

The object of the current exercise is, as I see it, to look at the various parts of the Preliminary Test and the Membership Examination in order to ascertain whether these instruments are adequately doing the job for which they are intended and, if not, to discover whether and in what ways they can be improved. It may also be asked whether there are any parts of the examination which are so ineffective that they should be discontinued and if so what should be substituted in their place.

\section{The Preliminary Test}

This is the simpler of the two examinations to analyse as, of course, it consists only of two parts: a multiple choice exam and an essay paper. Obviously the results obtained in each part need to be related to the other. Of those who have received their basic medical education in the United Kingdom, 56 per cent on average (range 49-61 per cent)* pass both parts while 13 per cent (9-19 per cent) fail both. The remainder are discrepant, rather more than 20 per cent failing the MCQ and passing the essay than vice versa-11 per cent. Thus the result of the MCQ (pass or fail) predicts the result of the essay question in 69 per cent of attempts made (range 64-72 per cent).

In the case of those graduates from the Middle East and the Indian sub-continent, much the same predictive value of the MCQ in respect of the essay paper is seen: (on average 60 per cent; range 54-64 per cent), although the number of attempts in which both MCQ and essay paper are failed (on average 45 per cent; range $38-49$ per cent) is almost four times as great than in the case of those of UK graduates. Likewise, the percentage of attempts leading to a discrepant result is higher for foreign graduates than those of the United Kingdom (those failing the MCQ and passing the essay = 33 per cent; vice versa $=7$ per cent).

A third much smaller group of heterogenous origin show results which lie between the two major groups, the results of

-All figures quoted refer to attempts made at passing the examination, not to the number of persons who made them. whose attempts have been quoted.

Combining all groups of whatever ethnic origin, it can be seen that those who pass both the MCQ exam and the essay paper in the Preliminary Test (Tests nos. 10-20 combined) is 34 per cent (1,209 candidates having made 3,540 attempts). Thirty per cent failed both parts, while in a further 36 per cent the results in each part were discrepant. (It should be noted, however, that the actual average pass rate over the same period was about 48 per cent, this because candidates failing on one part gained sufficient marks in the other to pass on aggregate. Here the MCQ marrs are again important as these appear to predict success or failure in the whole exam in 90 per cent of cases.)

A further comparison of the results raises considerable doubts as to whether the essay question paper as it is at present constituted, serves any very useful purpose, and if not, whether, as in the case of the first part of the MRCP (UK) exam, an MCQ would suffice to select those candidates who may be considered fit to proceed in due course to the main examination. Such a course of action would certainly be more economical, both of time as well as money.

Further support for this view may be gained by scrutiny of the marks awarded by pairs of examiners of the essay paper. The discrepancies which occur must, in many cases, be considered as not far short of alarming. Thus in the last 11 Preliminary Tests, pairs of examiners awarded marks which were pass/fail discrepant (i.e. one examiner awarded a pass mark, while the other failed the candidate) in from 26 to 39 per cent of cases. Concordant results ranged from 29 to 52 per cent where both examiners gave a pass mark, and 15 to 36 per cent where both gave a fail mark. Giving the examiners model answers from Preliminary Test No. 11 onwards appears not to have made the slightest difference to these results, possibly, either, because the examiners may not have read them or, more likely perhaps, because they did not agree with them.

In terms of marks awarded, the discrepant findings are, perhaps, even more disturbing. Remembering that marking is conducted on an 11-point scale (45-55) with 50 being the pass mark, only 14 to 22 per cent of both of a pair of examiners gave an identical mark, whereas all the remainder were discrepant in the award of one mark or more. Discrepancies of three, four or more marks are often evident, while in one test, one candidate was given marks of 48 and 55-the former a clear fail and the latter the highest possible, and in another, a candidate was awarded 45 marks by one examiner and 53 marks by the other-the former the lowest possible and the latter a mark in the range of excellence!

It is often said that essay questions should be retained because they test literacy, style, the ability to formulate 
knowledge and communicate, a capacity for reasoned argument and so on. But how much have these assumptions ever been tested? And, in any event, who are to be the judges? Without intending disrespect to the College's examiners, it can hardly be said that too many of them reveal in their own writings, even in replies to referral letters about patients, anything very much which could be construed as literacy finesse. Why should we not be honest about it? If it is language and literacy we really wish to test why not seek the services of an educationalist who is an expert in such matters and, furthermore, is likely to be unfettered by a preoccupation with psychiatric terminology?

Multiple choice questions have an undeservedly dubious reputation, usually among those who have not really studied the matter. Some say that there are many psychiatric topics which cannot be tested by this method. This, too, is an unproved assertion. Much depends on the skill of the question-setter. Nonetheless, however skilled he is, his questions must always be statistically validated. The computer often reveals that the very best-looking question is a discriminative flop. Others maintain that multiple choice questions are particularly hard on overseas candidates. Analysis of the figures does not bear this out. Although in the Preliminary Test examinations under scrutiny the results among overseas graduates were considerably worse than among those trained in this country, so were the results in the essay question paper. It is lack of knowledge, therefore, that fails the candidate rather than the method of testing. Thus at least $\mathbf{4 0}$ per cent of overseas candidates fail both parts of the examination, this, in one instance, being as high as 50 per cent. Some also say that MCQs are particularly hard on those who are of obsessional disposition and cannot make up their minds, particularly when a time factor is involved. But this, surely, also applies to other types of examination which can hardly be modified to suit the needs of obsessionals.

\section{The Membership Examination}

Much the same can be said of the written parts of the Membership Examination as for the Preliminary Test. However, the predictive value of the MCQ is somewhat lower than in the Preliminary Test, ranging from 64 to 75 per cent; so that about two-thirds to three-quarters of those who obtain a pass-mark in the MCQ will obtain sufficient marks in other parts of the exam to gain a pass, including, of course, the clinical exam in which a pass-mark is mandatory.

Although there is still a considerable discrepancy in essay question marks in the Membership examination, this is less striking than in the Preliminary Test, although it is disturbing to note that disagreement between the two marks of a pair of examiners as to who passes and who fails still ranges from 21 to 36 per cent, although there appears to be a higher degree of concordance between examiners in respect of those who achieve a pass-mark (46-70 per cent) than those who fail (9-21 per cent). Probably this higher concordance rate is because the essay examiners in the Membership find themselves more at home in dealing with material which is more familiar to them than the basic science questions set for the Preliminary Test.

Putting the need to test literacy ability aside, and the Membership exam itself is probably not the best occasion to attempt to do so, some consideration might perhaps be given to the use of short-answer as opposed to essay questions. Before this is accepted, however, a clearer idea needs to be gained of just what short-answer questions actually do test. They are certainly easier to mark than essays, if of course the rules of the game are carefully defined (e.g. how many words; what is to be included, etc.). It has also to be determined whether short-answer questions can test anything which the MCQ cannot adequately do.

Clinicals and oral examinations: what can be done to improve these? The usual kind of clinical examination in which the candidate presents his long case to a pair of examiners, but in which the patient is unseen by the examiners themselves so that there is no observation of the candidate actually at work, is probably of limited value. However, the logistical difficulties of extending the examination process in order to overcome this problem are considerable. Having one of the examiners spending some time observing each candidate interviewing is almost certainly desirable. A mere peek at the patient is not enough.

One difficulty with psychiatric clinical examinations is that there are virtually no short cases as such which are suitable for examination purposes. Here the psychiatric examiner is at a disadvantage in comparison to his medical or surgical colleagues, who in their clinical examinations make great use of short cases having interesting physical signs which require elicitation and interpretation.

I have no doubt that so far as psychiatry is concerned that video-tape recordings do go some way to correcting this deficiency, provided they are properly produced and presented under optimum conditions. Experiments in Birmingham with this method of examination suggest that the best way to use them is in combination with an oral exam, the video-tape excerpt shown to the candidate being used as a talking point. However, even when this is done experimentally, the correlation of marks with those of the clinical or the non-video tape oral is not altogether as high as might be expected. There is a suggestion, furthermore, that the video-tape oral does not test the same abilities as a clinical exam or an ordinary oral. This may be in part due to a lack of familiarity on the part of the examiners with the medium when used for this purpose. However, there is some evidence that video-tape recordings do test a candidate's powers of observation. If this is correct, inclusion of the method as part of the whole examination can be regarded as potentially very valuable.

But even if desirable, the procedure is undoubtedly expensive, requiring not only satisfactory apparatus 
conforming to a set standard, but technical on-the-spot expertise in order to cope with maintenance and minor faults if and when these arise. One other point not apparently generally realized is that an identical video-tape is not necessary for use in every examination centre. After all the patients whom the candidates are asked to examine are by no means identical, but vary widely. With video-tapes variation is by no means a disadvantage; indeed it may allow economies to be made in that a tape used in one centre can subsequently be used in another.

In summary I would recommend as follows:

In the Preliminary Test the exam should consist of a multiple choice questionnaire only. The existing essay paper should be dropped. If a test of literacy is thought to be desirable, then a properly designed written test examination should be devised in order to test this quality without regard to factual information. Expert help in this matter should be sought.

In the Membership Examination consideration should be given to replacing the essay paper by short-answer questions provided these can be shown to fulfil a function other than that covered by the multiple choice questionnaire. Secondly, in the clinical examination a way should be found of allowing one or both examiners to spend sufficient time with the candidate during the time he is actually examining his patient. Thirdly, there should be an additional oral examination, again of about 20 minutes duration, in which video-tape excerpts should be shown. Finally, a detailed analysis of the results of all parts of the Membership Examination should continue as at present.

\section{Mental Health Guardianship - a Change for the Better?}

\section{Gareth W. Hughes, Consultant Psychiatrist, Cefn Coed Hospital, Swansea}

The 1959 Mental Health Act has provided the legal framework for psychiatric practice in the UK for the past two decades. The Mental Health (Amendment) Bill (DHSS, 1981) currently before Parliament proposes to update the Act by improving the safeguards for detained patients, clarifying the position of staff looking after them, and by the removal of uncertainties in the law. The Bill incorporates changes relating to the compulsory care of Mentally Disordered patients in the community whereby a person may be accepted into Guardianship on the grounds that he or she is suffering from a Mental Disorder. Once accepted into Guardianship, the person or body named as Guardian has the power to exercise control over the person as if he or they were the father of the patient, and the patient was under 14 years of age.

In its Report, the Percy Commission (DHSS, 1957) envisaged that Guardianship would be useful for persons with mild or chronic forms of Mental Illness as an alternative to prolonged hospitalization. In practice Guardianship has been used predominantly for the Mentally Handicapped, and only rarely for the Mentally III. Its use has declined over the years, and in the 12 months ending March 1978 only 37 patients in England and Wales diagnosed as Mentally III were made subject to Guardianship, compared with over 18,000 compulsory admissions to Mental Hospitals (DHSS, 1981).

Although much has been written on the principles of compulsory care of Mentally Disordered patients in the community, and in support of the retention of such a facility (Royal College of Psychiatrists, 1979; BASW, 1977; Gostin,
1975), there has been little published research into its decline and disuse. Unlike Treatment or Observation Orders, Guardianship invariably places responsibility on Local Authorities. The extent to which Guardianship is used, therefore, depends largely on the attitude and policy of the relevant Authority.

In an attempt to establish the position of Local Authorities with respect to Guardianship, a questionnaire was sent to the Directors of Social Services of 29 randomly selected Local Authorities representing one in four London, Metropolitan, and Non-metropolitan Authorities in England and Wales. Enquiries were made regarding the extent of current usage, trends in usage, the type of patient supervised, policy regarding use or restrictions on use and practical difficulties encountered in supervision.

Twenty replies were received including five letters declining to comment or referring the matter to the Association of Directors of Social Services. The 15 replies varied considerably both in information provided and in attitude towards Guardianship. Approximately half of the Departments had not accepted a patient into Guardianship over recent years, notably since the reorganization of Local Government in 1974. Although most Authorities expressed major reservations regarding Guardianship, only three admitted to having a firm policy of avoiding its use. Most Departments had fewer than three clients under supervision, the patient invariably being Mentally Handicapped. Most Authorities felt that the precise powers conferred by the Act were unclear, and if anything, rather limited. The Order merely provided the legal authority without the practical 